\title{
EL SIGNIFICADO DEL PRINCIPIO DE LEGALIDAD EN LA ADMINISTRACION MODERNA
}

\author{
Por JULIO A. PRAT \\ Profesor titular de la Cátedra de Derecho Administrativo \\ de la Facultad de Derecho y Ciencias Sociales de la Universidad Mayor \\ de la República [Montevideo, Uruguay)
}

Sumario: 1. Los origenes históricos del principio de legalidad.-2. La incidencia de los principios generales de Derecho, en especial en el Derecho uruguayo.-3. El principio de juridicidad en la Administración moderna.-4. Conclusiones.

\section{Los origenes históricos del principio de legalidad}

La sumisión del Poder ejecutivo a la ley se cumplirá con el advenimiento del Estado de Derecho. La noción «Estado de Derecho» se la utiliza para oponerla al Estado policía, que, aunque encontró sus máximos exponentes en el Absolutismo Ilustrado, ha permanecido vigente en muchos países de la Tierra, aun en nuestros días. Por otra parte, no ha habido una definición unánimemente aceptada respecto a qué se entiende por Estado de Derecho, y además a cuál Derecho. No obstante, su uso se hace corriente desde que Von Mohl utilizara la expresión en el sentido de aqquel Estado que tiende a disciplinar la vida del pueblo de modo que cada miembro del mismo se encuentra sostenido en el ejercicio y en el uso lo más posible libre de sus propias fuerzas", y agregaba: "es fundar el Estado en la libertad de los ciudadanos". 
DA-1980, núm. 187. JULIO A. PRAT (URUGUAY). El significado del principio de legalidad en I...

$Y$ es Orlando, en 1900, quien preverá una definición finalista del Estado de Derecho: «El que asegura la libertad de los ciudadanos, preservándolos del poder y del arbitrio de la autoridad", que será, con variantes, la acepción más admitida y reproducida en los textos de nuestra disciplina. Estado de Derecho es aquel que preserva entonces los derechos subjetivos de los ciudadanos del mismo, oponiendo al ejercicio del poder público garantías esenciales que permiten a aquéllos poseer garantías suficientes para defenderlos.

Cuando el Estado de Derecho adviene, sucediendo al Estado absolutista, se opera una profunda transformación en la autoridad central. Hasta este momento, el soberano absoluto crea, hace y produce el Derecho, que es su derecho (legibus solutus); sólo está sometido al derecho natural de carácter providencial, siendo responsable sólo ante Dios. Ahora, la autoridad está limitada, sometida a la norma general, a una regla jurídica que representa la voluntad general, producto del pacto social. En el mejor léxico de Rousseau, la Ley da, como manifestación de la soberanía de la mayoría, movimiento y voluntad al Estado.

La Ley emerge como principio y norte de toda la actividad estatal, y la Administración (léase Poder ejecutivo) se somete a la Ley. El que detenta el poder se somete a la norma general, abstracta, impersonal. Es el ideal del Gobierno, por y en virtud de las leyes. $\mathrm{Y}$ el Poder ejecutivo, en una distribución primaria de las funciones del poder, emergerá sometido a esta norma, ya que su única actividad será de «ejecutar y hacer ejecutar las leyes, dictando los reglamentos necesarios para ello". Esta fórmula, que tradicionalmente se ha repetido en todas las Constituciones del mundo civilizado, se presenta como la mejor expresión de la competencia reglada de un ejecutivo débil. Si bien la fórmula será recibida en muchas Cartas del Viejo y Nuevo Mundo, la realidad será otra, ya que con esta simplista fórmula jurídica el Poder ejecutivo dictará reglamentos autónomos, prescindiendo de la norma legal que debia ejecutar y dando entrada al poder discrecional de la Administración.

La Administración, ligada a la Ley, regla externa, será maniatada aún más con la aparición del constitucionalismo. Si bien ya los británicos hablaban de Cartas y de Bills, es la Cons- 
DA-1980, núm. 187. JULIO A. PRAT (URUGUAY). El significado del principio de legalidad en I...

titución de los Estados Unidos de Norteamérica que aportará la gran innovación. Es quizás la curiosidad de la historia, que nos enseña que este Estado, a diferencia de Gran Bretaña y de Francia, nace a la vida independiente como Estado y como Estado de Derecho. La libertad individual en él es un presupuesto del propio Estado desde su iniciación, sin ser un resultado de una conquista frente a un Estado poderoso y arbitrario como lo fue la Regencia borbónica en Francia, o la cruenta y sangrienta lucha entre rey y Parlamento en Inglaterra. El proceso se invierte: la libertad individual se la reconoce como presupuesto esencial desde el inicio del Estado independiente; pero será este Estado que deberá ir conquistando lentamente sus prerrogativas de Poder público, una vez creado.

El sometimiento a la Ley dará nacimiento al principio de legalidad, fuertemente vinculado al Estado de Derecho. Administración no sometida a la norma legal no es Estado de Derecho. Así lo entendieron los revolucionarios de 1789, reconociendo, por un lado, la existencia de una norma jurídica superior, general, abstracta, impersonal, de la cual emanen todas las potestades públicas, incluidas las propias de la Administración, la cual, en el ejercicio de sus actividades, debe estar subordinada a ella. Los mandatos abstractos normativos legales reconocen en esta etapa mecanismos simples y primarios de ejecución de esa legalidad, caracterizada por un simple particularismo de aplicación concreta a cargo del Poder ejecutivo. Así nace el concepto de acto administrativo y prosperará el examen de legalidad de los mismos, ya que éstos deben estar en consonancia con aquéllos.

Eisenman (1) distingue en la noción de la legalidad una máxima y una minima. La máxima, como relación de conformidad de adecuación fiel a lo que la norma legal manda. Es la competencia reglada de la Administración (2). La mínima, como de "no contrariedad" o compatibilidad del comportamiento de la Administración a la norma jurídica legal.

(1) Eisenman: *Le Droit administratif et le principe de legalité, en Etudes et Documents du Conseil d'Etat, 1957, 11, p. 25.

(2) Señala Waline, prólogo al libro de Siassinopouzus: Traité des actes aáministratifs, Atenas, 1954, que el Derecho administrativo podría definirse actualmente como: el estudio del poder discrecional de las autoridades administrativas y de sus limites. 
DA-1980, núm. 187. JULIO A. PRAT (URUGUAY). El significado del principio de legalidad en I...

El constitucionalismo estadounidense influirá sobre los revolucionarios franceses, creando un nuevo nivel jurídico y sacudiendo el principio de legalidad. La Constitución se ubica por encima de la norma legal y en un esquema positivista, frío y académico, a lo Kelsen $\mathrm{y}$, en nuestra disciplina, Merkl, quienes reaccionaron contra esta afirmación, por demás deficiente, de la legalidad administrativa. La pretendida formación del Derecho por grados nos está señalando que el proceso de la producción del ordenamiento jurídico es una legis executio, quizás paulatina, pero siempre a partir de la ley fundamental. Si la Administración aparece inserta en este proceso necesariamente, o en una fase del mismo, no hace otra cosa que ejecutar la Ley - las normas superiores (Constitución y Ley), respetando los grados de primacía o las normas antecedentes. Pero, a juicio de Winkler, hay una vinculación positiva que no es desdeñable, y que consiste en que la Administración actúa fundada en la Ley o vinculada al ordenamiento jurídico (3). Esta nueva interpretación implicará grandes transformaciones en la interpretación del pretendido principio de legalidad. La obra de los Foundings Fathers de Filadelfia hará entrar una nueva norma. la constitucional, que amplía los horizontes del ordenamiento normativo.

$\mathrm{Su}$ proyección en los revolucionarios franceses tendrá un efecto irradiante para las Cartas de las nuevas naciones latinoamericanas, operando una influencia masiva con profundas consecuencias sobre el principio de la legalidad. El esquema de Rousseau (4) se ve profundamente alterado. La Ley es una nor-

(3) Milkier, pp. 36 y ss., distingue la legalidad en un sentido negativo: La Ley opera como un límite externo a una básica libertad de determinación del Ejecutivo (es un poder discrecional) y en un sențido positivo: La Administración debe actuar sobre el fundamento de la Ley ( aau Grund der Gesetze» del artículo 20 numiral 3 de la Ley fundamental de Bonn). También Celso Antonio Bandeira de Meluo; aDiscrecionalidad administrativa y control judicial», en Anuario de Derecho Administrativo, tomo I, Santiago de Chilo, 1975-76, pp. 445 y ss. Cassagne: El acto administrativo, Buenos Aires, 1978. Fronini: Teoria juridica del acto administrativo, Buenos Aires, 1969. Vidal Perdomo: Derecho Administrativo, Calf, Colombia, 1977. Oriveira Franco Sobainho: Curso de Direito Administrativo, San Pablo, 1979, tomo I. GordrLo: El acto administrativo, 2." ed., Buenos Aires, 1879. Dnow: Instituciones de Derecho Administrativo, Buenos Aires, 1973; etc.

(4) Derecho Administrativo, tomo I, Montevideo, 1977, pp. 31 y ss., y Prat-MontesQUIBU: *L'esprit des Lois, el principio de separación de poderes, su proyección y vigencias, en Estudios de Derecho Administrativo, Montevideo, 1979, publicación de la Universidad de la República en homenaje al centenario de la creación de la cátedra de Derecho administrativo. 
DA-1980, núm. 187. JULIO A. PRAT (URUGUAY). El significado del principio de legalidad en I...

ma infraconstitucional, subordinada a la norma constitucional, que es la que conduce y dicta el arte jurídico en forma primaria y original. La Ley le está subordinada, y en algunos casos está desplazada por el dictado de reglamentos autónomos autorizados por el propio texto constitucional.

\section{La incidencia de los principios generales de Derecho}

Pero no es sólo el constitucionalismo que altera el principio de la legalidad. Este se amplia por un principio de juridicidad, comprendidos los textos constitucionales, pero esto no alcanza. En países como Uruguay el texto constitucional da entrada en su artículo 72 de la Constitución a una norma de carácter excepcional y con un recibo muy limitado en los paises de Occidente.

Este artículo 72 culmina la declaración de derechos individuales y los de contenido económico y social, disponiendo: "La enumeración de derechos, deberes y garantías hecha por la Constitución no excluye los otros que son inherentes a la personalidad humana o se derivan de la forma republicana de gobierno", cierra la sección II de la Constitución, $y$, por ser recibido en un texto de máximo valor formal, da ingreso a toda una estimativa jus naturalista que se funda en los principios fundamentales del derecho natural. Esto es importante, porque significa el abandono definitivo de toda posición positivista, además de toda normativa kelseniana (5).

Por un lado, al tener estos principios un genérico reconocimiento constitucional, participan de la suprema jerarquía normativa (Constitución) y de una Carta rígida, por lo que se ubican al mismo nivel, por encima de la Ley, lo que implica reconocer que se benefician del contralor de inconstitucionalidad de las leyes y de decretos-leyes en el caso eventual de que éstos los desconozcan (6).

(5) Real: Estado de Derecho y humanismo pérsonalista, Montevideo, 1974, y del mismo autor, "Los principios generales de Derecho», en Rev. de Derecho público y Privado, 1958.

(6) PRAT: Derecho Administrativo, tomo 11, p. 98. 
DA-1980, núm. 187. JULIO A. PRAT (URUGUAY). El significado del principio de legalidad en I...

Estos principios, detectados por una jurisprudencia vacilante del Consejo de Estado francés (7) y creando serios problemas interpretativos a éste (8), reconocen en Uruguay un texto constitucional expreso que los admite, poniendo fin a toda discusión de ubicación.

Cualquiera que sea la posición filosófica que frente al Derecho se pueda sostener, aun encerrado en un crudo positivismo, la inserción de este artículo en el ordenamiento jurídico uruguayo incorpora al mismo los principios fundamentales no escritos, inherentes a la personalidad humana y a la forma republicana de gobierno. Con él la doctrina uruguaya se vio libre de padecer todas las dudas y discusiones que se plantean en los países del área occidental, tratando de determinar los origenes de los principios generales del Derecho, su ubicación entre las fuentes del Derecho administrativo y su eficacia.

Ya la norma constitucional, ya los principios generales del Derecho reconocidos expresamente en la Carta, dando ingreso a igual valor formal, a los inherentes a la personalidad humana (estimativa jus naturalista) y a los que derivan de la forma repubblicana (democrática) de gobierno, ubicadas por encima, en cuanto a valor formal, de la Ley, inciden en el principio de legalidad. Es que ya no es la Administración, que debe ejecutar la Ley dentro del cuadro estrecho de la legalidad, observándola en su actual, sino que el ámbito se amplía. y el sometimiento se hace a todo el ordenamiento jurídico, o por lo menos a las normas superiores: Constitución, Principios y Ley. El principio de legalidad es sustituido por uno más amplio, más extenso: el de la juridicidad o el de la legitimidad en sentido amplio y omnicomprensivo de toda la normativa del ordenamiento jurídico. Así reza la Carta fundamental de Bonn, 1949: la Administración debe actuar "conforme a Derecho", o, en el mejor léxico de Maurice Hauriou, al bloque de la legalidad, tomada ésta en sentido amplio.

(7) RIvero: Le juge administratif, juge qui gouverne, en Dalloz 1951, Chronique, pp. 21 y ss., y del mismo autor, \&Los principios generales de Derechow, en Rev. de Administración Pública, 1951, p. 296. V. VeDEL: Droit administratif, Parfs, 1973, pp. 282 y siguientes, y Rrvero: Droit Administratif. Paris, 1973, pp. 75 y $5 s$.

(8) VEDEL, p. 282, y RIVERO, pp. 75-76. 
DA-1980, núm. 187. JULIO A. PRAT (URUGUAY). El significado del principio de legalidad en I...

Nuestro texto constitucional, en su artículo 309, al precisar la competencia anulatoria del Tribunal de lo Contencioso-Administrativo, señala que éste conocerá de las demandas de nulidad de actos administrativos definitivos, dictadas por los órganos administrativos en el ejercicio de sus funciones, "contrario a una regla de Derecho o con desviación de poder» (9). El artículo 345 de la Ley 13.318, de 24 de diciembre de 1974, precisa que, por «regla de Derecho" debe entenderse «todo principio de Derecho, o norma constitucional, legislativa, reglamentaria o contractual", recibiendo una concepción amplia que podemos denominar el haz de la juridicidad.

\section{El principio de juridicidad en la Administración moderna}

Es indudable que el principio de juridicidad es el fundamento de la validez del actuar administrativo actual. El apartamiento de éste de aqué debe ser sancionado con la nulidad de sus actos, atribuyéndose esta facultad a jurisdicciones de gran jerarquía, imparciales e independientes, especializadas en Derecho público, al servicio del deseado equilibrio entre las potestades públicas para el logro del bien común y de los derechos administrados,

Es en este sentido que el juez administrativo emerge como el guardián oficial de la regularidad jurídica de los actos, y en especial de la compatibilidad de su contenido con la regla de Derecho, en particular con la Ley.

Esta conformidad o esta compatibilidad ha sido alcanzada seriamente, a medida que se ha transformado la Administración, a consecuencia de la aparición de nuevos cometidos que se le han atribuido o que se han variado los conceptos de los que anteriormente detentó. Nuevos procedimientos de gestión, la invasión de Administración en órbitas anteriormente reservadas exclusivamente a los particulares, la regulación económica y la planificación, el acondicionamiento de las áreas territoriales en el cumplimiento de políticas de desarrollo social, hacen de la

(9) La referencia a ala desviación de poder* es un pleonasmo, ya que es ilegalidad en cuanto al elemento finalidad del acto. V. Prat: La desviación de poder, Montevideo, 1975, 2." ed. 
DA-1980, núm. 187. JULIO A. PRAT (URUGUAY). El significado del principio de legalidad en I...

Documentación

Administración una gestora que ya no ejecuta, como tradicionalmente se la ha considerado, fijando las grandes direcciones, orientando la actividad privada en los sectores de la economía, en que su discrecionalidad se amplía enormemente y que muchas veces ésta resulta incontrolable, por la trascendencia de los objetivos globales que se quieren alcanzar.

El dictado de reglamentos autónomos se ha hecho mucho más frecuente en nuestro siglo que lo que fue en el siglo pasado, en que la Administración estaba relegada a ser una simple ejecutora de la Ley en una actividad sumamente relegada. Este siglo es el siglo del Poder ejecutivo, como el pasado lo fue del Parlamento. Ello significa reconocer un cierto desequilibrio entre los poderes estáticos, en que el más perjudicado resulta el legislativo. Es posible que éste, a pesar de gozar de una primacia tradicional inspirada en el sistema parlamentario a la inglesa, exhiba ciertas carencias que lo hacen difícilmente adaptable a la intervención estatal, conformando el orden económico y social. El Poder legislativo, debido a la falta de celeridad para adoptar las medidas necesarias de adaptación de las situaciones cambiantes que toda planificación reclama, irá perdiendo potestades en forma gradual, hasta llegar a la solución francesca de 1958, en que la forma legal se ve reducida a regular un limitado número de materias, transformándose la regla en excepción. Hemos sostenido (10) que, «dentro del esquema básico del Estado de Derecho, la Administración continuará sometida al principio de juridicidad, pero deberán admitirse nuevas soluciones que se aparten de la concepción tradicional del principio de separación de poderes. Asi encontramos todas las formas de legislación delegada que tanto preocupó a la doctrina de Derecho público de principios de siglo, y la extensa ampliación de la potestad reglamentaria del Poder ejecutivo, frente a la reducción considerable del ámbito de regulación legislativa, como sucedió con la Constitución francesa de 1958. En contrapartida, los contralores sobre la acción del Poder ejecutivo se verán reforzados con una serie de institutos que en su conjunto podrian agruparse en lo que otrora Mirkine Guetzevith llamó la racionalización del poder».

(10) PRAT: Derecho administrativo cit., tomo I, pp. 79 y ss. 
DA-1980, núm. 187. JULIO A. PRAT (URUGUAY). El significado del principio de legalidad en I...

Pero, por otro lado, la Administración moderna se distingue de la de la época clásica porque, al atribuírsele extensísimos cometidos, requiere nuevos medios $\mathrm{y}$ nuevos procedimientos de instrumentación jurídica para alcanzarlos y lograrlos, y reclama también profundas reformas orgánicas, funcionales y burocráticas. La concentración de potestades en el ejecutivo imponen una fuerte centralización, en perjuicio de los entes institucionales, que se ven afectados en su autonomía anterior; la concentración impone la aparición de ciertos organismos, de carácter técnico en su mayoria, que van a actuar en estrecha colaboración y en tareas de asesoramiento del Poder central, dispersando la responsabilidad de la decisión; se utilizan nuevas técnicas de información y gestión al nivel de los adelantos científicos más recientes y de los actuales medios de difusión de ideas; la creación de nuevas áreas territoriales distintas de las tradicionales, provincias, comunas, departamentos, dando ingreso a nuevas personas jurídicas a nivel regional, bi o multinacional, etc.; todo ello importa una necesidad imperiosamente urgente de contar con un personal altamente calificado, eficaz y de alto nivel cultural, que constituirá una de las herramientas fundamentales para el logro de los objetivos asignados.

La planificación, en la búsqueda de cambios lentos y graduales de estructuras sociales, transformó a la Administración del período clásico, de ordenadora, en conformadora del orden económico y social. Ya no es vigilar y mantener el orden público y ejecutar la Ley; su tarea ahora debe conformar el orden económico y social, transformándolo en aras del bienestar común. Pero nuevamente surge el escollo del desajuste de la labor parlamentaria con las nuevas técnicas y los nuevos procedimientos que el ejecutivo reclama. La regulación legislativa de la conformación resulta imposible hacerse por leyes sumamente detalladas, por lo proteico de la materia a reglar. De ahi que se imponga a normas legales que formulan vagas e imprecisas enumeraciones de objetivos (leyes esqueleto, leyes cuadro, etc.), o autorizaciones genéricas o particulares a cada caso a la Ad. ministración, para que ella la regule discrecionalmente (delegación legislativa). 
DA-1980, núm. 187. JULIO A. PRAT (URUGUAY). El significado del principio de legalidad en I...

Se ha reaccionado contra estas alteraciones; que en cierto sentido llevan a que la Administración moderna esté cada vez menos subordinada al Derecho, o que esta subordinación sea cada día más tenue y que pueda devenir puramente teórica. De ahí que la doctrina haya propuesto la sujeción de la nueva Administración, conformadora a los postulados esenciales del Estado de Derecho, sometiéndola en su accionar al cumplimiento de normas jurídicas aún reglamentarias, precisas y de fácil inteligencia y a un contralor jurisdiccional estricto en cuanto al respeto al haz de la juridicidad. Más aún, ante la enorme extensión de su poder discrecional, se ha instalado un contralor de méritos que complementa el contralọ jurisdiccional de legalidad, importándose institutos como el Ombudsman sueco y adaptándolo a las necesidades internas de cada país.

Pero, además de conformadora, la Administración moderna es prestacional. Responde a la idea básica del Estado social de Derecho, sucesor del Estado liberal. $Y$ es prestacional porque muchas de sus actividades se traducen en prestaciones que contemplan el imperioso desarrollo de la civilización industrial, que a su vez reclama su partipicación directa en los fines propuestos. Sólo el principio de subsidiariedad puede jugar como un límite de contención al respecto. Toda esta situación reflejada en la Administración pública ha provocado la aparición de nuevos procedimientos. Surge una denominada aAdministración concentrada", en que el administrado cada vez está, por un lado, más corrientemente en contacto con la Administración; por otro lado, ésta prefiere dar participación (concierto) a los administrados en su gestión, teniéndolos de colaboradores, que de recurrir a la decisión unilateral imperativa, librada a su solo criterio de decisión.

Administración conformadora, prestacional, aseguradora de la sociedad globalmente considerada, partidaria de la concertación más que de la decisión imperativa adoptada aisladamente, dotados de amplias potestades discrecionales, encontrará siempre un límite permanente en los fines que debe perseguir: el bien común, el interés público, del cual no podrá apartarse, y que para su logro le fueron concedidas las potestades que 
DA-1980, núm. 187. JULIO A. PRAT (URUGUAY). El significado del principio de legalidad en I...

detienen. Si al cumplimiento del fin propuesto el ordenamiento jurídico exige la motivación de sus actos, es decir, la expresión clara y precisa de los motivos que la llevan a actuar o a no actuar, la Administración quedará obligada a confesar los fundamentos de su acción y facilitará a los contralores de juridicidad y de méritos si se observaron o no las finalidades concretas que explicita. Podrá argüirse que la predominancia de consideraciones técnicas de eficacia o los requerimientos de una flexibilidad, acentuado en el accionar administrativo, podrían superar este límite. Aunque no dejamos de reconocer que los. contralores que se ejerzan podrán ser menos intensos, estándose a los logros alcanzados, igualmente consideramos que en muchos casos esta exteriorización de los motivos sigue prestando utilidad como fórmula de contención de desbordes.

\section{Conclusiones}

En resumen, podemos señalar:

A) EI principio de legalidad que encuadró antaño a la Administración y a su acción, y en los límites de la norma legal, ha debido ser sustituido por uno más amplio, el de juridicidad contentivo de las normas constitucionales, legales y reglamentarias, además de los principios generales de Derecho.

B) En Uruguay, la recepción en el texto constitucional de estos principios generales inherentes a la persona humana y a la forma republicana de gobierno amplía a nivel de máximo valor normativo formal el contenido del principio de juridicidad.

C) La. moderna Administración pública, con la ampliación. de nuevos cometidos, ha aumentado su poder discrecional en muchas de las gestiones que debe cumplir. La observancia del principio de la finalidad y la exteriorización de los motivos por los cuales la Administración decide importan una importante valla que, a la vez que puede contener el desborde de la Administración, facilita enormemente el contralor de juridicidad y de: mérito de sus actos. 
D) El principio de juridicidad continúa siendo el fundamento de la validez de la acción de la Administración.

E) Si bien la labor legislativa se ve dificultada por una serie de circunstancias que la ponen en desventaja por falta de adaptación a los nuevos tiempos, es necesario, para continuar en un Estado de Derecho, que se dicten leyes precisas concretas e inteligibles, que faciliten a los encargados de los contralores el examen del ajuste de las decisiones a dichas normas.

F) Es en el contralor jurisdiccional de legalidad o en el de institutos especiales, Ombudsman, o contralorías al estilo venezolano o chileno, donde la salvaguardia del Estado de Derecho reside. De ahí que estas magistraturas deben ser imparciales, independientes y con titulares de gran jerarquía para poder cumplir con el papel importantísimo que se les ha asignado. Es así como se asegurará él también - ¿por qué no decirlo?- de la propia Administración y de sus prerrogativas. 